\title{
Phonological Adaptation of Hokkien Loanwords in Indonesian
}

\author{
Uti Aryanti \\ Department of Chinese Language and Literature, Peking University, China \\ Email: utiaryanti@pku.edu.cn
}

Submitted: 09/11/2020

Revised: 28/12/2020

Accepted: 17/01/2021

E-ISSN : $2579-4574$

P-ISSN : 2549-7359

\begin{abstract}
The Chinese loan words in Indonesian mainly come from the Hokkien. Many scholars have studied the Hokkien loanwords in Indonesian, but they analyzed from the perspective of semantics and culture, and there is still little research on phonological adaptation. This research attempts to answer three questions, namely, what phonological adaptation do the Hokkien loanwords in Indonesian have in the process of being accepted? Are there sound correspondences between Hokkien loanwords in Indonesian? What are the phonological rules for phonological adaptation of Hokkien loanwords in Indonesian? This research is mainly based on the literature method and comparative research method. Data were collected through literature search and recording. The collected data were processed for natural hearing, a comparative analysis of two Indonesian Hokkien speakers' sound production, and four Indonesian speakers' sound production is conducted. The sound production of the speakers are segmented and coded manually using Praat Version 6.0 (Boersma \& Weenink, 2015) focused on the measurements of the acoustic parameters of the sounds produced differently by the two groups of informants and, finally, summed up. Since Indonesian has a more uncomplicated vowel system and a different consonant inventory, when we look at the Hokkien loanwords in Indonesian, we will observe many substitution rules. To maintain the Indonesian syllable structure and phonological restrictions, the Indonesian phonological rules that appear in certain environments are considered to apply to Hokkien loanwords.
\end{abstract}

Keywords: Language contact, Hokkien loanwords, Phonological adaptation

\section{https://ojs.unm.ac.id/eralingua}

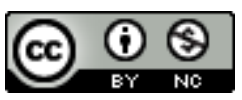

This work is licensed under a Creative Commons Attribution-NonCommercial 4.0 International License 


\section{INTRODUCTION}

Chinese loanwords in Indonesian mainly come from the Hokkien. In the Indonesian dictionary studied, Kong (1987) found a total of 507 Chinese loan words, of which a rough check showed that at least 454 were from the Hokkien, accounting for $89.5 \%$ of the total Chinese loanwords in Indonesian. In some Indonesian dictionaries, the reason why the Hokkien loanwords account for so many Chinese loanwords is due to historical and social factors.

After 1900, most Chinese in Indonesia came from southern China, mainly the Guangdong and Fujian provinces. Wen and Hong reported in 1985 that the government's 1930 census of the origins of 1,190,014 Chinese Indonesian illustrates the language background of these immigrants. People from Fujian accounted for $47 \%$ of the Chinese Indonesian population, followed by Hakka (17\%), Cantonese (11\%), and Chaozhou (7\%). These four regions are in southern China, and the hometown of the remaining $18 \%$ is unknown. The native language of most Chinese Indonesian is not the modern standard Chinese (also known as Mandarin) because their ancestors are Han people in southern China, and they mainly use these three Chinese dialects: Fujian-Taiwanese Hokkien (Hokkien), Hakka, and Cantonese. Besides, the Hokkien sub-dialect of the Chinese Indonesian of Teochew origin, Teochew and Hokkien, can have a certain degree of mutual intelligibility (Skinner, 1963). According to Lewis (2005) in "Indonesia", Ethnologue: Languages of the World (15th ed.), in 1982, a survey of the language use of 2 million Chinese Indonesians were conducted in 1,100,000 people using Hokkien dialects (Quanzhang and Teochew); 640,000 people using Hakka; 180,000 people using Cantonese; and Hokkien (including Fuzhou dialect) there are 20,000 people. Also, an estimated 20,000 Chinese are using different dialects of Indonesian. The relationship between the Chinese and their country of residence is getting closer, and they are in contact with each other in social life. In this case, the Chinese must form language contact with the language of the country of residence.

Language contact often leads to language change. Linguists usually refer to this type of language change as a contact-induced language change. There are two modes of language change caused by contact: borrowing and shift-induced interference. Borrowing means that foreign elements are incorporated into the native language of the language community by the speakers of that native language. The mother tongue of this language community was maintained but changed due to the addition of foreign elements (Thomason \& Kaufman, 1988). The borrowed language can be called the receiving language (referred to as the recipient language), and the foreign language can be called the source language (referred to as the source language). It shows that the agent of borrowing is the speaker of the recipient. The most common borrowing interference is the vocabulary component.

Many scholars have studied Hokkien loanwords in Indonesian. The result of the research of Leo (1975) and Jones (2008) is a list of Chinese loanwords (Mandarin, Cantonese, Hokkien, and Hakka dialects). Kong (1987) and Kabul (2007) mainly studied the semantic changes and semantic fields of Hokkien loanwords in Indonesian during the process of being accepted. Lin (2016) and Tang (2016) 
analyzed the history, formation, ways, types of Chinese loan words in Indonesian, and the relationship between Chinese loan words and culture, society, religion, and politics. Most of those researches are analyzed from the perspective of semantics and culture. Although Kabul (2007) and Yang (2008) studied the pronunciation of Hokkien loan words in Indonesian in the process of being accepted, their analysis did not involve phonetic and phonological adaptation. Kabul (2007) after performed phonetic analysis, she founded changes in consonants, vowels, and diphthongs. Consonant changes include (1) no changes in the pronunciation part; (2) changes in the pronunciation part; (3) addition and omission of consonants. The changes of vowels are divided into (1) vowel changes; (2) vowel addition; and (3) vowel omission of the original word. Yang (2008) believes that by analyzing the phonetic of Hokkien loanwords in Indonesian, one can find that since the phonetics of Hokkien is separate systems from those of Indonesian languages, both Hokkien native speakers and Indonesian native speakers have been adaptively modified the phonetics of the Hokkien words that need to be introduced or borrowed based on the Indonesian phonetic system. The Indonesian phonetic system is used to modify the pronunciation of Hokkien words that are not suitable for it so that the phonetics of the recommended or borrowed Hokkien words can conform to the phonetics of the Indonesian phonetic system.

This research attempts to answer three questions, namely, what phonological adaptation do the Hokkien loanwords in Indonesian have in the process of being accepted? Are there sound correspondences between Hokkien loanwords in Indonesian and Indonesian? What are the phonological rules for phonological adaptation of Hokkien loanwords in Indonesian? The answers to the above questions enable us to understand the phonological rules of the sound variation of Hokkien loanwords in Indonesian.

\section{RESEARCH METHOD}

To limit the scope of the research, I defined the operational definition of this research. In this article, Indonesian is the official language of the Republic of Indonesia; the Hokkien is Hokkien of the Xiamen family because the most borrowed words in the database are Hokkien from the Xiamen family. This article defines loanwords, namely phonemic loanwords. Phonemic loanwords are words that are partially borrowed in phonemic form, borrowing both sound and meaning. Loanwords must adapt to the phoneme structure, phonetic and phonological rules, and pronunciation habits of the borrowed language. It is the definition of phonemic change in this article. The result of this sound change process is the sound variation referred to in this article.

This research is mainly based on the literature method and comparative research method. Data were collected through literature search and recording. The informants, namely Indonesian Hokkien speakers and Indonesian speakers, were asked to read the vocabulary lists and record the readings. After collecting the materials, the collected data was processed for natural hearing, a comparative analysis of Indonesian Hokkien speakers sounds production and Indonesian speakers sound production was conducted, they were segmented and coded manually using Praat Version 6.0 (Boersma \& Weenink, 2015) focused on the 
measurements of the acoustic parameters of the sounds produced differently by the two groups of informants and summed up. The specific research procedure is as follows: First, collect written materials of Hokkien loanwords and make a vocabulary list. Due to time constraints, this article decided to use the vocabulary of Chinese Loanwords Spoken by the Inhabitants of the City of Jakarta as Bahasa Indonesia by Leo (1975). Leo listed 70 Hokkien loanwords that he formulated, but after analyzing and comparing (based on Loanwords in Indonesia and Malay, 2008), it was found that only 68 of the 70 words are phonemic loanwords, 60 loanwords in Hokkien among 68 loanwords, and the other loanwords (8 loanwords) are non-Hokkien. Among the 60 Hokkien loanwords, the most are the loanwords from the Xiamen Hokkien, that is, 43 loanwords. Other loanwords of Hokkien are from the Zhang family (16 loanwords) and Quan family (1 loanword). Secondly, the native speakers of Indonesian Hokkien and the native speakers of Indonesian were asked to read the vocabulary aloud and recorded it. Then, a natural hearing analysis was conducted to analyze sound variation. Sound variation analysis was based on replacement rules and phonological constraints. Sound correspondence was performed after analyzing the sound variation. Finally, the phonological rules of the sound variation were summarized.

There was a total of six speakers in this research survey, all Indonesians aged between 20 and 60 years old, representing native speakers of Indonesian Hokkien and Indonesian native speakers. The first informant is an Indonesian Hokkien speaker, graduate student, male, 27 years old; the second is also an Indonesian Hokkien speaker: graduate student, female, 22 years old; the third is a native Indonesian speaker, retirees, male, 64 years old; the fourth is a native Indonesian speaker, a housewife, 61 years old; the fifth is a native Indonesian speaker, a graduate student, female, 23 years old; the last is a native Indonesian speaker, an undergraduate student, male, 21 years old. The basic information of all informants is shown in the following table.

Table 1. The basic information of informants

\begin{tabular}{lllccc}
\hline Informants & Nationality & $\begin{array}{c}\text { Mother } \\
\text { tongue }\end{array}$ & $\begin{array}{c}\text { Age } \\
\text { (years } \\
\text { old) }\end{array}$ & Gender & Occupation \\
\hline Informant A & Indonesian & Hokkien & 27 & Male & $\begin{array}{c}\text { Graduate } \\
\text { student }\end{array}$ \\
\hline Informant B & Indonesian & Hokkien & 22 & Female & $\begin{array}{c}\text { Graduate } \\
\text { student }\end{array}$ \\
\hline Informant C & Indonesian & Indonesian & 64 & Male & Retirees \\
\hline Informant D & Indonesian & Indonesian & 61 & Female & Housewife \\
\hline Informant E & Indonesian & Indonesian & 23 & Female & $\begin{array}{c}\text { Graduate } \\
\text { student }\end{array}$ \\
\hline Informant F & Indonesian & Indonesian & 21 & Male & $\begin{array}{c}\text { Undergraduate } \\
\text { student }\end{array}$ \\
\hline
\end{tabular}




\section{RESULT AND DISCUSSION}

When a natural hearing analysis was conducted, it was found that out of the 60 borrowed words, the speakers of Indonesian Hokkien only recognized 48 loanwords. After analyzing the measurements of the acoustic parameters of the sounds produced differently by the native speakers of Indonesian Hokkien and the native speakers of Indonesian, it was found that 14 of the 48 loanwords have no phonological changes, and 34 words have phonological changes. The result of this sound change process is sound variation. The sound variation analysis was based on replacement rules and phonological constraints. Below is a summary of the results of the sound variation analysis.

\section{Substitution Rules}

Phonological substitution refers to the phenomenon of phoneme assimilation that occurs when foreign words are absorbed into the native language. Foreign sounds that are not in the native language system are generally replaced by the most similar sounds (Mei, 2017). The characterization of phonemic substitution can be divided into vowel substitution and consonant substitution. The following are the phonemic substitution types of Hokkien loanwords in Indonesian during the process of being accepted.

1. Palatalization

Hokkien and Indonesian have a different place of articulation for affricates. Hokkien affricates are apico-alveolar consonants, which means it is articulated with the tip of the tongue, while Indonesian affricates are articulated with the blade of the tongue or known as laminal alveolar consonants. Therefore, when Hokkien loanwords containing affricates are accepted in Indonesian, the apico-alveolar consonants [ts] and [dz] are replaced by laminal alveolar consonants [t] and [d3], for example:

Hokkien

Indonesian

2. Vowel Raising

There are also differences in the vowel system between Hokkien and Indonesian. The back vowels of Hokkien are composed of three sounds: mid-low vowel [0], mid-high vowel [o], and high vowel [u], while Indonesian only has the back vowels of the mid-high vowel [o] and high vowel [u]. Therefore, when Hokkien loanwords containing [0] are accepted in Indonesian, this vowel is replaced by [o], for example:

\begin{tabular}{|c|c|c|}
\hline & Hokkien & Indonesian \\
\hline (4) & [k미k므] & [konko] \\
\hline (5) & [tekọ] & [teko] \\
\hline
\end{tabular}


Hokkien [o] and [u] have no changes in Indonesian, for example:

(6) [kojo?] [kojo?]

(7) [kuts'ai] [kut]aj]

3. Deaspiration

The Hokkien phonetic system distinguishes between aspirated consonants and unaspirated consonants, while in the Indonesian phonetic system, there is no opposition between aspirated consonants and unaspirated consonants. Loanwords in the Hokkien language omit the part of aspiration in the process of being accepted. For example, aspirated consonants [ts'] and [t'] are replaced by unaspirated consonants $[\mathrm{t}]$ and $[\mathrm{t}]$ :

$\begin{array}{lll} & \text { Hokkien } & \text { Indonesian } \\ \text { (8) } & \text { [ts'aisim] } & \text { [t]ajsim] } \\ \text { (9) } & \text { [t'auke] } & \text { [toke?] }\end{array}$

4. Denasalization

Hokkien has the opposition of nasal and non-nasal vowels, while Indonesian does not. Therefore, the Hokkien loanwords in Indonesian omit the nasal vowels in the process of being accepted. For example:

$\begin{array}{lll} & \text { Hokkien } & \text { Indonesian } \\ \text { (10) } & \text { [siupiã }] & \text { [sopjạ] } \\ \text { (11) } & \text { [səmpoã }] & \text { [səmpowąa? }\end{array}$

\section{Phonological Constraints}

The sound changes that have been discussed are substitutions of sounds. In this section, we will look at sound changes that are affected by the conditioning environment. The constraints are phonological terms. It refers to specific statements about the various forces that trigger and prevent language change. For example, phonotactic constraints are statements about the sequence of the segments that may appear in the syllables of a specific language. The sequence of segments such as [pn] violates the constraints of the first sound of English and is, therefore, unlawful. (Mei, 2017). The following are some sound changes affected by the environment.

1. Glottal Velarization

When the glottal sound in the Hokkien loanword appears at the end of the word, it becomes the velar sound [k] in the process of being accepted by Indonesian.

$$
\begin{aligned}
& \mathrm{P} \rightarrow \mathrm{k} / \_ \text {]word } \\
& \text { For example: }
\end{aligned}
$$
Hokkien
Indonesian
(3)
[dzo? ]
[djok] 
$\begin{array}{lll}(12) & {[\text { bakja? }]} & \text { [bakjak }] \\ (13) & {[\text { tiojko? }]} & \text { [tijonkok }]\end{array}$

2. Indonesian Phonotactics

In the syllable structure part, it is mentioned that Indonesian is a multisyllable language. In Indonesian, a syllable with two vowels connected is not allowed. There are two glide sounds in Indonesian, namely the bilabials $/ \mathrm{w} /$ and the palatal approximant /j/. There are two phonetic behaviors associated with Indonesian glide sounds $/ \mathrm{w} /$ and $/ \mathrm{j} /$, namely (i) at the beginning of a syllable, $/ \mathrm{w} /$ and lj/ have consonant functions (ii) at the end of a syllable, /w / And /j/ are the diphthong parts (Alwi, et.al, 2003: 76). Samsuri (1981) and Verhaar $(1982,1996)$ claimed that glide has corresponding vowels, and Indonesian $/ \mathrm{w} /$ and $/ \mathrm{j} /$ have corresponding vowels $/ \mathrm{u} /$ and $/ \mathrm{i} /$. Not only that, but the glide is also like its corresponding vowel. The vocal cords vibrate during pronunciation, and the airflow is not obstructed by the articulator. In other words, it is not like when consonants are pronounced, there is an obvious process of blocking, holding, and removing blocks. On the contrary, the state of its place of articulations and the articulators are also the same as the corresponding vowels. The consonant component is only expressed as slight friction during the pronunciation process, and this friction can sometimes be so slight that it is difficult to detect. In this sense, the glide is a consonant with a dominant vowel. This is an important characteristic. Also, in syllable combinations, glide cannot form a syllable alone but must be combined with vowels. This is where it is consistent with other consonants. The difference is that its combination is generally not as free and flexible as other consonants. For example, the glide in Indonesian only appears in certain syllables, and there are certain conditions, namely at the beginning and the end of the syllable, such as /wa dzah/'face', /sa ja/'I', /lam paw /'past', /pan daj/'smart; capable'.

A diphthong is a sound that inherits the sound quality of two vowels: the start-vowel (on-glide), the end-vowel (off-glide), and the transition segment. The formation of two consecutive vowels in the oral cavity of a syllable results in sliding from the start-vowel to the end-vowel, which is usually called a diphthong. A diphthong is also defined as an independent vowel-glide, which means that the articulator starts from the position of one vowel and moves in the direction of the other vowel. A diphthong is also related to the movement pattern of the formant frequency diagram, starting from the start-vowel part of the diagram and ending at the end-vowel part. For example, this feature can be observed in the English diphthong [ar], which includes the drawing changes from the start-vowel [a] segment to the end-vowel [I] segment.

Glide is a sound that is phonetically similar to a vowel sound, but unlike vowels, glide does not constitute a prominent part of the speech signal in the syllable. It is why glide cannot form a syllable alone in Indonesian like vowels. This kind of consonants has some acoustic characteristics that are similar to vowels, such as periodic output waveform and clear formant structure. Due to the welldefined formant structure, the glide is often called semi-vowel. Glide is a speech that is considered to have a gradually changing formant pattern, in the same way as 
the diphthong pattern changes. It is why the acoustic analysis of glide in this article is carried out together with the analysis of diphthong. As mentioned above, glide does not remain steady, and this feature distinguishes them from vowels. However, since the two sounds gradually change the formant pattern, it is difficult to distinguish glide from diphthong. Glide is a sharp and short semi-vowel, so the transition period of these sounds is shorter than the transition period of diphthong because the channel configuration in the process of glide production comes in and out quickly. The difference between glide and diphthong is difficult to determine because these two sounds cannot maintain a steady-state but have a gradually changing formant pattern.

Sounds with acoustic characteristics similar to glide are vowels and diphthongs. Such similar acoustic characteristics include periodic output waveforms and a clear formant structure, in which most of the energy exists in the first formant. The only consonant class (glide) with a clear and predictable formant structure may confuse the identification of three types of speech: glide, diphthong, and vowel. The difference between a vowel and a glide is very simple: it does not maintain a steady state, while the vowel remains a steady state. However, the difference between glide and diphthong is difficult to determine because these two sounds cannot maintain a stable state. On the contrary, they are sounds with gradually changing formant patterns.

When Hokkien words are borrowed into Indonesian, they must also follow the above syllable structure rules. This article relies on the acoustic analysis of the transitional section of glide and diphthong to identify the VV structure of Hokkien words when borrowed into Indonesian to become VC or CV. A diphthong is a combination of two vowels and has an important analysis point: transition (the transition duration between the first and second vowels). To quantify the acoustic characteristics of Indonesian diphthong and glide, the main acoustic parameters measured are the previous formant (F1, F2) and the time of the transition period. The two formants provide basic clues for the perception of monophthong vowels. However, the second formant is considered to be one of the most basic acoustic cues for diphthong perception. [Vj], [jV] or [ $\mathrm{Vw}],[\mathrm{wV}]$ sequence shows shorter total duration, earlier transition to [_V] and/or faster transition. Location-based characterization can also predict the acoustic evidence that [j] and [w] are more anterior than [i] and [u], so it has a higher $\mathrm{F} 2$. In contrast, the contraction-based representation predicts that [j], [w] have a lower sound intensity and therefore have a lower F1.

To simplify the vowel cluster of the Hokkien syllable, the following four strategies can be used. The rules can be stated as follows.
(a) $\mathrm{C}_{1} \mathrm{~V}_{1} \mathrm{~V}_{2} \rightarrow \mathrm{C}_{1} \mathrm{~V}_{1} \mathrm{C}$
condition: $V_{2}=\mathrm{i} 、 \mathrm{u}$

The sound change that occurs here is the vowel changes to glide. This vowel becomes glide when it is at the end of the syllable and it is placed behind other vowels. [i] becomes [i] when it is placed after the vowel and at the end of the syllable:

$$
\mathrm{i} \rightarrow \mathrm{j} / \mathrm{V} \_ \text {] } \sigma
$$


For example:

$\begin{array}{ll}\text { Hokkien } & \text { Indonesian } \\ \text { [ts'aisim] } & \text { [t } \text { Jajsim] } \\ \text { [tsapts'ai }] & \text { [t } \text { Japt }[\text { Jaj] }\end{array}$

The differences in the acoustic characteristics of the diphthong [ai] pronounced by native Indonesian Hokkien speakers with the sound [aj] pronounced by native Indonesian speakers can be seen on the spectrogram in Figures 1 and 2 below.

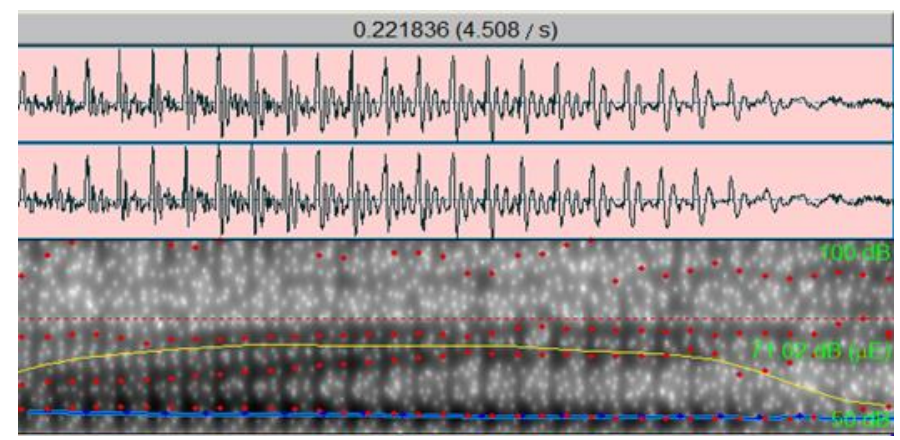

Figure 1. Spectrogram for [ai] diphthong spoken by Hokkien native speakers

Duration: $221 \mathrm{~ms}$; F2 max : $2024 \mathrm{~Hz}$; F1 min: $454 \mathrm{~Hz}$

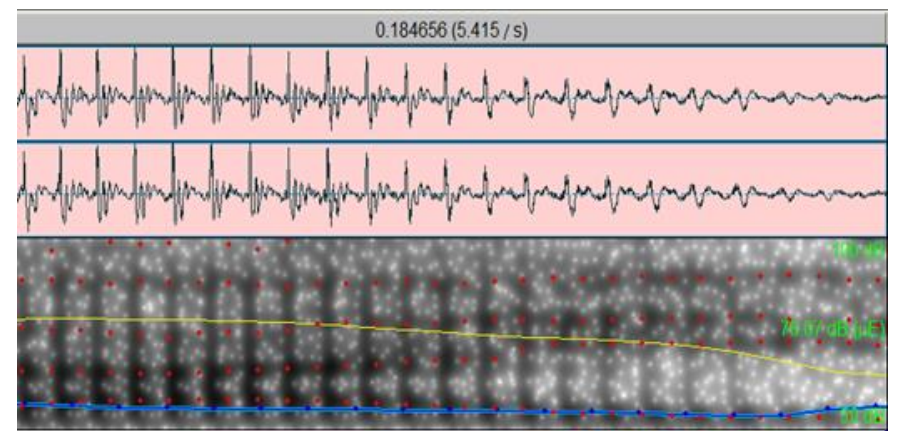

Figure 2. Spectrogram for [aj] spoken by Indonesian native speakers

Duration: $184 \mathrm{~ms}$; F2 max: $2237 \mathrm{~Hz}$; F1 min: $378 \mathrm{~Hz}$

As explained above that the $[\mathrm{Vj}],[\mathrm{jV}]$, or $[\mathrm{Vw}],[\mathrm{wV}]$ sequence shows a shorter total duration than diphthong. The duration of [aj] as seen in Figure 2 is 184 $\mathrm{ms}$, while the duration of the diphthong [ai] in Figure 1 is $221 \mathrm{~ms}$. [j] is more anterior than [i], so it has a higher F2. In contrast, the contraction-based representation predicts that [j] have a lower sound intensity and therefore have a lower F1.

The same process as [i], [u] becomes [w] when it is in the environment where the vowel is placed after the other vowels and at the end of the syllable:

$\left.\mathrm{u} \rightarrow \mathrm{w} / \mathrm{v}_{\ldots}\right] \sigma$

For example:

Hokkien

Indonesian

(16) [ba?pau]

[bappaw]

(17) [tauge]

[tawge] 
Figure 3 and Figure 4 show the differences in the acoustic characteristics of the diphthong [au] pronounced by native Indonesian Hokkien speakers with the sound [aw] pronounced by native Indonesian speakers.

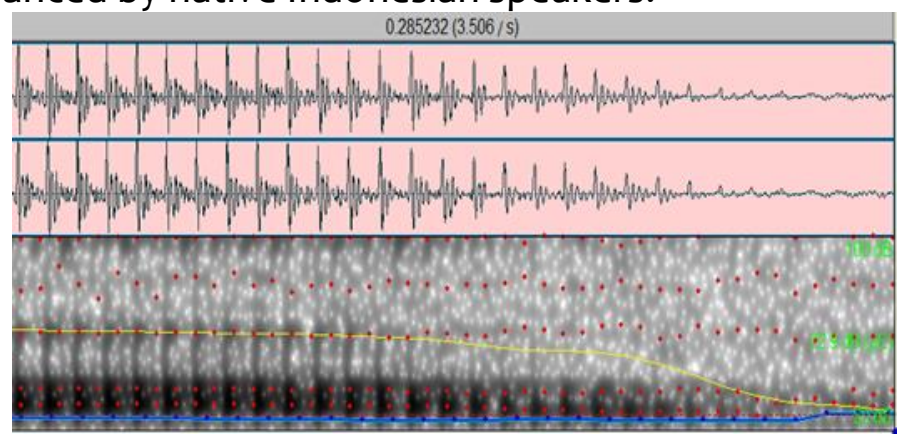

Figure 3. Spectrogram for [au] diphthong spoken by Hokkien native speakers

Duration: $285 \mathrm{~ms}$; F2 max: $1079 \mathrm{~Hz}$; F1 min: $601 \mathrm{~Hz}$

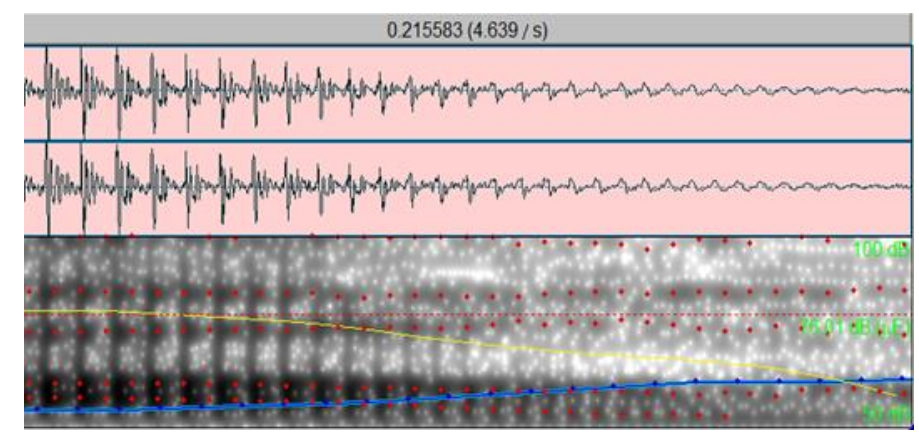

Figure 4. Spectrogram for [aw] spoken by Indonesian native speakers

Duration: $215 \mathrm{~ms}$; F2 max: $1161 \mathrm{~Hz}$; F1 min: $382 \mathrm{~Hz}$

In Figure 3, we can see that the sequence [aw] has a shorter duration, which is $215 \mathrm{~ms}$ than diphthong [au] in Figure 3 which is $285 \mathrm{~ms}$. The consonant [w] is more anterior [u], so it has a higher F2. Besides, [w] has a lower sound intensity and therefore has a lower F1.

(b) $\mathrm{C}_{1} \mathrm{~V}_{1} \mathrm{~V}_{2} \rightarrow \mathrm{C}_{1} \mathrm{CV}_{2} \quad$ condition: $\mathrm{V}_{1}=\mathrm{i}$

Rule (b) is a kind of phonological change that belongs to the composition of glide, that is, the process in which the core vowel in the syllable loses its core position and becomes the first glide. As can be seen from the above example, the core vowel [i] becomes glide [j].

$$
\left.\mathrm{i} \rightarrow \mathrm{j} / \_\mathrm{V}\right] \sigma
$$

This is a typical gliding process. For example:

$$
\text { Hokkien Indonesian }
$$

(10) [siupiã] [sopja]

This sound change is the same as the sound change as described by rule (a), which is the change of a vowel sound to a glide, the difference is only in the position 
of the vowel that changes. Therefore, the acoustic differences saw in Figure 5 and Figure 6 also have the same explanation as those shown in Figure 1 to Figure 4.

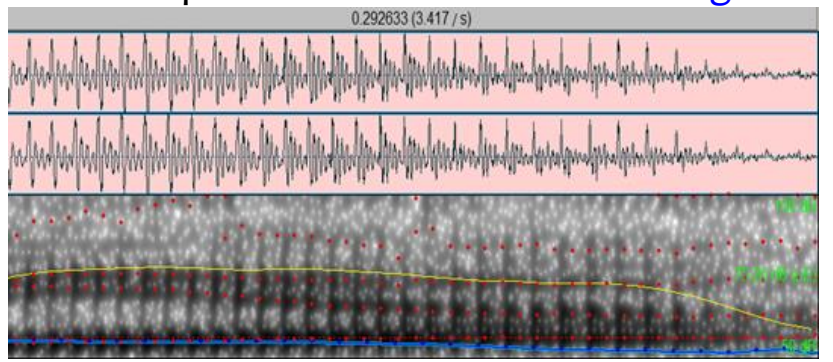

Figure 5. Spectrogram for [ia] diphthong spoken by Hokkien native speakers

Duration: $292 \mathrm{~ms}$; F2 max: $2181 \mathrm{~Hz}$; F1 min: $430 \mathrm{~Hz}$

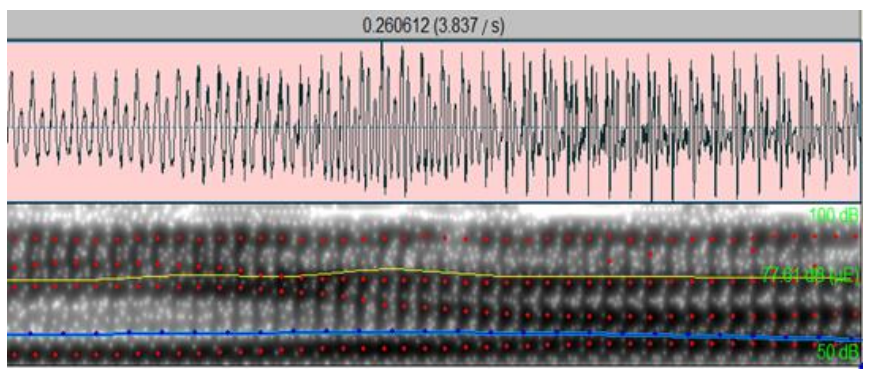

Figure 6. Spectrogram for [ja] spoken by Indonesian native speakers

Duration: $260 \mathrm{~ms}$; F2 max: $2413 \mathrm{~Hz}$; F1 min: $322 \mathrm{~Hz}$

The sequence [ja] in Figure 6 has a shorter duration than diphthong [ia] in Figure 5 . Its F2 value is higher than [ia] because [j] is more anterior than [i], but its F1 value is lower than [ia] because [j] has a lower sound intensity than [i].

(c) $\mathrm{C}_{1} \mathrm{~V}_{1} \mathrm{~V}_{2} \rightarrow \mathrm{C}_{1} \mathrm{~V}_{1} \mathrm{CV}_{2} \quad$ condition: $\mathrm{V}_{1}$ 和 $\mathrm{V}_{2} \neq \mathrm{i}$

$$
\left.\phi \rightarrow \mathrm{w} / \mathrm{V}_{1} \_\mathrm{V}_{2}\right] \sigma
$$

This kind of phonological change refers to the insertion of the glide. The insertion of glide means that the pronunciation of the core vowel of the syllable continues to the first position of the following syllable. It also means the process of inserting a glide having the same place of articulation at this position. For example:

$\begin{array}{lll} & \text { Hokkien } & \text { Indonesian } \\ \text { (19) } & {[\text { kuatsi] }} & {[\text { kuwatfi] }} \\ \text { (20) } & {[\text { kue }]} & {[\text { kuwe }]}\end{array}$

Sound change in the form of glide insertion is still a sound change that shows the relationship between the vowel and the glide, in this case, the vowel $[u]$ and the glide [w]. Figure 7 and Figure 8 show the acoustic difference between the two sounds based on the acoustic parameters of duration, F1, and F2 values, respectively. 


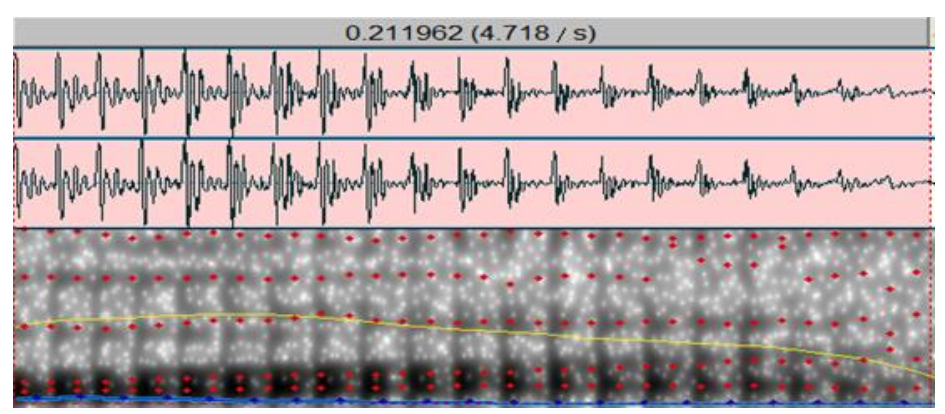

Figure 7. Spectrogram for [ua] diphthong spoken by Hokkien native speakers

Duration: $211 \mathrm{~ms}$; F2 max: $1112 \mathrm{~Hz}$; F1 min: $474 \mathrm{~Hz}$

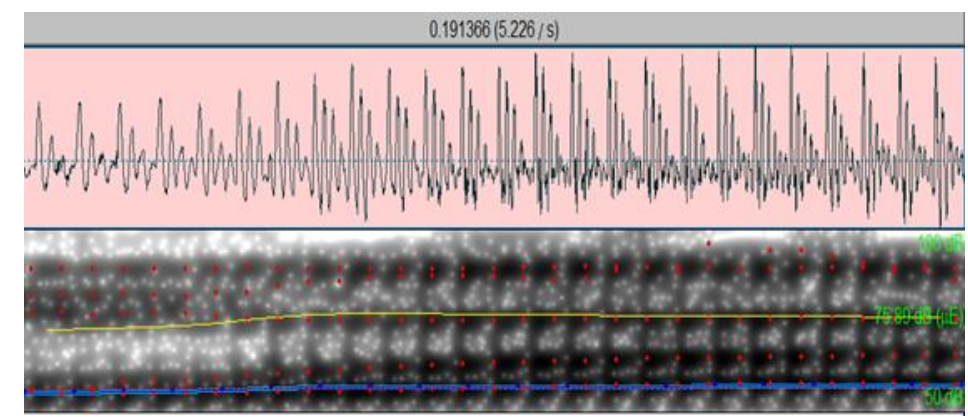

Figure 8. Spectrogram for [wa] spoken by Indonesian native speakers

Duration: $191 \mathrm{~ms}$; F2 max: $1451 \mathrm{~Hz}$; F1 min: $452 \mathrm{~Hz}$

From the above example, we can see that the number of syllables of Hokkien words changed after borrowing into Indonesian. Because of the glide insertion, when one syllable of a Hokkien word is borrowed into Indonesian, it becomes two syllables. For example, the word [kue] is originally composed of one syllable, but because of the insertion of glide [w] becomes [kuwe], so [w] becomes the first sound of the second syllable. The core vowel $[\mathrm{u}]$ of the first syllable is pronounced in the same position as the first sound $[\mathrm{w}]$ of the second syllable.

(d) $\mathrm{C}_{1} \mathrm{~V}_{1} \mathrm{~V}_{2} \rightarrow \mathrm{C}_{1} \mathrm{~V}$

The transformation of diphthong into single vowels is the process of this kind of voice change. The process is so-called monophthongization, that is, the process in which the sound quality of vowels changes from diphthong to single vowels. For example:

$\begin{array}{lll} & \text { Hokkien } & \text { Indonesian } \\ \text { (10) } & {[\text { siupiã }]} & {[\text { sopja] }} \\ \text { (21) } & \text { [toapckon] } & \text { [təpekon] }\end{array}$

From the above analysis results, I tried to make the phonetic correspondence between the Hokkien loanwords and the Indonesian language. The following is the sound correspondence table. 
Table 2. The sound correspondence between Hokkien loanwords and Indonesian

\begin{tabular}{ccc}
\hline No. & Hokkien & Indonesian \\
\hline 1. & ts/ts' & $\mathrm{t} \int$ \\
\hline 2. & $\mathrm{t}^{\prime}$ & $\mathrm{t}$ \\
\hline 3. & $\mathrm{dz}$ & $\mathrm{d} 3$ \\
\hline 4. & $?$ & $\mathrm{k}$ \\
\hline 5. & 0 & $\mathrm{o}$ \\
\hline 6. & a & $\mathrm{a}$ \\
\hline 7. & ai & aj \\
\hline 8. & au & aw \\
\hline 9. & ia & ja \\
\hline 10. & io & jo \\
\hline 11. & ua & uwa \\
\hline 12. & ue & uwe \\
\hline 11. & iu & o \\
\hline 12. & oa & 2a \\
\hline
\end{tabular}

Since the phonological systems of Hokkien and Indonesian are different, Hokkien loanwords have some sound variations in the process of being accepted, which are as follows.

1. The Indonesian language does not distinguish between aspiration and nonaspiration; it does not differentiate between nasal vowels and non-nasal vowels. Indonesian is also a non-tonal language. Therefore, the tones, aspirated sounds, and nasal vowels of Hokkien loanwords disappeared during the process of being accepted in Indonesian.

2. From the perspective of the place of articulation of consonants, the difference between Hokkien and Indonesian lies in the apex (tongue tip) and laminal (tongue blade) sounds. Hokkien has apex consonants, but Indonesian does not. Conversely, Indonesian has laminal consonants, while Hokkien does not. In this case, the apex consonants of the Hokkien loanwords become the laminal consonants during the process of being accepted in Indonesian.

3. From the perspective of vowels, the difference between Hokkien and Indonesian back vowels lies in the height of the tongue. The back vowels of Hokkien are composed of three sounds: o (mid-low vowel), o (mid-high vowel), and $u$ (high vowel), while Indonesian only has the back vowels of o (mid-high vowel and $u$ (high vowel). Therefore, when a Hokkien loanword containing a mid-low vowel is accepted by Indonesian, this vowel is replaced by a mid-high vowel.

4. When the glottal sound in the Hokkien loanword appears at the end of the word, the glottal sound becomes the velar sound [k] in the process of being accepted by Indonesian.

5. In the syllable structure part, Indonesian is a multi-syllable language. In Indonesian, a syllable with two vowels connected is not allowed, while the phonetic system of Hokkien allows diphthong. Therefore, in the process of 
acceptance in Indonesian, the diphthong of the loanwords in Hokkien has the phenomenon of glide formation, glide insertion, and monophthongization.

The above are the main phonological rules for the sound variation of Hokkien loanwords in Indonesian during the process of being accepted.

\section{CONCLUSION}

I have reported the major phonological sound changes that take place when Hokkien words are borrowed into Indonesian. Because Indonesian has a simpler vowel system and a different consonant inventory, when we look at the Hokkien loanwords in Indonesian, there are substitution rules: palatalization, vowel raising, deaspiration, and denasalization. To maintain the Indonesian syllable structure and phonological restrictions, the Indonesian phonology rules that appear in a specific environment are considered to apply to Hokkien loanwords. Although there seem to be some regional and social linguistic changes to determine the application of some of these rules, the rules reported in this article represent most of the Hokkien loanwords that exist in Indonesian. This research is still very imperfect and still needs to be studied in depth. Future research needs to collect more data so that the research results can be more comprehensive. Finally, I hope that this research will lay the foundation for future research.

\section{ACKNOWLEDGEMENTS}

This research was supported by Peking University's Li Xiaofan Dialectology Research Grant 2020 managed by the Department of Chinese Language and Literature, Peking University.

\section{REFERENCES}

Alwi, H (et.al). (2003). Tata Bahasa Baku Bahasa Indonesia. Balai Pustaka.

Boersma, P., \& Weenink, D. (2015). Praat: doing phonetics by computer [Computer program]. https://www.fon.hum.uva.nl/praat/

Jones, R. (gen. ed.). (2008). Loanwords in Indonesian and Malay. KITLV \& Yayasan Obor Indonesia.

Kabul, A. R. (2007). Kata Serapan Bahasa Hokkian: Subdialek Xiamen dalam Bahasa Indonesia. Fakultas IImu Pengetahuan Budaya Universitas Indonesia.

Kong, Y. (1987). A Study of Chinese Loanwords (South Fujian Dialect) in the Malay and Indonesia. Journal of the Humanities and Social Sciences of Southeast Asia and Oceania 143 (4).

Leo, P. (1975). Chinese Loan-words Spoken by the Inhabitants of the City of Jakarta. LIPI.

Lewis, M. Paul, ed. (2005), "Indonesia", Ethnologue: Languages of the World (15th ed.). SIL International.

Lin, X. (2016). Xīnjiāpō Mǐnnánhuà Yĩngyǔ jiècí de yīnxì fènxī (Phonological adaptation of English loanwords in Singapore Hokkien) (Unpublished masters' thesis). The National University of Singapore.

Mei, D. (2017). Yǔyánxué yǔ yīngyòng yǔyánxué băikē quánshū (Encyclopedia of Linguistics and Applied Linguistics. Beijing University Press. 
Samsuri. (1981). Analisis Bahasa. Penerbit Erlangga.

Skinner, G. William. (1963). 'The Chinese minority', in R.T. McVey (ed.), Indonesia. Survey of World Cultures (Southeast Asia Studies, Yale University), 97-117, New Haven (CT): Human Relations Area Files.

Tang, G \& Guo Xi. (2016). Yìnníyǔzhōng de Hànyǔ jiècí (Chinese loanwords in Indonesian). Yǔyán Wénzì Yìngyòng, (3), 144.

Thomason, Sarah \& Terrence Kaufman. (1988). Language Contact, Creolization and Genetic Linguistics. University of California Press.

Verhaar, J. W. M. (1982). Pengantar Linguistik. Gadjah Mada University Press.

Verhaar, J. W. M. (1996). Asas-asas Linguistik Umum. Gadjah Mada University Press.

Yang, Q. (2008). Yìnníyǔ Mǐnnánhuà jiècí jí qí yánjiū de wénhuà yǔyánxué sīkăo (Cultural and Linguistic Ponder of Hokkien Loanwords in Indonesian and It's Research). Shǒujiè Hǎiwài Hànyǔ Fāngyán Guójì Yántǎohuì (The first International Conference on Overseas Chinese Dialects). 